\title{
La televisión de alta definición en el proyecto de modernización de la industria televisiva mexicana
}

\author{
Octavio Islas Carmona \\ Instituto Tecnologico y de Estudios Superiores de \\ Monterrey (ITESM) - Campus Estado de México
}

\section{El papel de la televisión en la modernización de la sociedad mexicana}

ESDE SUS inicios en la década de los cincuentas, la industria televisiva mexicana se ha articulado sobre la base del modelo estadunidense de televisión. ${ }^{1}$ Sin embargo, a diferencia de la abierta competencia que hasta nuestros días todavía sostienen entre sí las principales cadenas de la Unión Americana, en México las condiciones han sido propicias para que un consorcio - Televisa ${ }^{2}$ - se proyecte como virtual monopolio, dispuesto a acceder a su plena internacionalización durante la presente década.

En México, la televisión se ha convertido en los últimos treinta años en una de las principales palancas de modernización de la sociedad. ${ }^{3} \mathrm{Su}$ discurso ha sido lo

1 Oriol Costa (1986:21), afirma que las principales características del modelo estadounidense radican en que éste es de tipo privado y con finalidades comerciales.

2 El 8 de enero de 1973 se anunció la creación de Televisa, producto de la fusión de los canales 2, 4 y 5 , pertenecientes a Telesistema Mexicano, con el canal 8 de Televisión Independiente de México. Los canales 2,4 y 5 previamente se habían fusionado entre sí el 26 de marzo de 1955, dando lugar a Telesistema Mexicano, Por su parte, el canal 8 inició operaciones el primero de septiembre de 1968, cubriendo el IV Informe de Gobierno del Presidente Gustavo Diaz Ordaz, aunque sus transmisiones regulares dieron comienzo hasta 1969. Este pertenecía a los prósperos industriales del Grupo Monterrey.

3 Sobre el relevante papel que ha desempeñado Televisa en la modernización de la sociedad mexicana, Aguilar Camín (1988:244-245), puntualiza que: "en el último cuarto de siglo (la sociedad mexicana) ha visto cumplirse una revolución cultural silenciosa: la implantación de un refinado aparato de comunicaicón masiva, cuyo personaje estelar es la televisión. Ningún medio anterior de comunicación - el ferrocarril o el telégrafo, las carreteras o la radio, el teléfono o el cine - ha tenido un efecto integrador de la conciencia mexicana como el surgimiento de la televisión". 
suficientemente contundente y eficaz para poder uniformar la conciencia colectiva y dirigir el consumo del país, hasta crear, ante la constante indecisión del Estado, lo que Héctor Aguilar Camín atinadamente denomina como "una zona compartida de la experiencia nacional".

Aunque las complejas realidades regionales apenas existen en la lógica del consorcio, Televisa se ha convertido en una especie de sofisticado termómetro, capaz de definir el alcance y sentido de los criterios de lo anacrónico y lo moderno. En la exclusiva pasarela del "Canal de las Estrellas" día con día se verifica una silenciosa ruptura con los valores de la sociedad tradicional premoderna. Por medio de su extraña simbiosis de medio hogareño y vanguardia modernizadora (Aguilar Camín, 1988), Televisa se encuentra en condiciones de establecer una nueva sensibilidad estética, ${ }^{4}$ susceptible de ser exportada a la mayor parte de hispanoparlantes en el mundo, gracias a la impresionante cobertura que registra el principal canal del consorcio en tres continentes.

Como destacada protagonista de nuestros ambiciosos proyectos de modernidad, donde la televisión participa activamente de la reinauguración de los tiempos mexicanos, ${ }^{5}$ Televisa ha iniciado una delicada reconversión tecnológica, aunque sin modificar algunas de sus terribles prácticas internas, ${ }^{6}$ mismas que irremediablemente limitan el alcance de su pretendida mutación.

\section{La HDTV dentro de los proyectos de Televisa para el fin del milenio}

En 1990 se inició en Televisa un ambicioso proceso de reajustes y transformaciones. En el panorama nacional, estas inesperadas medidas modificaron, de inmediato y sustancialmente, la perspectiva del modelo mexicano de televisión posible. Dentro de estos importantes cambios destaca la modificación de la participación de los

4 Como tecnología de punta, la televisión es en sí misma innovación y moda. Construye buena parte de las representaciones colectivas del mexicano, dirige su ocio y consumo, articula la cultura popular a partir del establecimiento de la educación informal y los escaparates de la vida deseable.

5 Uno de los más agudos análisis que se han realizado sobre la naturaleza y problematicidad del tiempo mexicano es, sin lugar a dudas, el realizado por Carlos Fuentes.

6 La empresa permanece ajena a todo intento democratizador y solidario. En sus prácticas informativas predomina la desinformación. Para colmo, la nueva élite de su "talento artístico" se recluta de los hijos y parentela de los artistas pioneros. Esta misma tendencia se observa en los cuadros directivos. Es la esperada hora de los herederos. 
principales accionistas, resultando significativo el desplazamiento de dos de sus directivos: Miguel Alemán (hijo de Miguel Alemán Valdés, presidente de México en el periodo 1946-1952, que precisamente corresponde al momento histórico en que el Estado otorgó las primeras concesiones de televisión a particulares), y Rómulo O'Farril Jr., magnate del periodismo en México. Fue así como todo el control de Televisa quedó en manos de su accionista mayoritario y responsable de su formidable despegue: el próspero empresario Emilio Azcárraga Milmo.

Por lo que corresponde al escenario internacional, ante el umbral del próximo fin de milenio, el poderoso consorcio perfiló sus primeros pasos hacia su conversión como una de las principales cadenas televisivas del mundo, por miedo de la incorporación de la HDTV.

Conscientes del inevitable advenimiento de una amplia transformación tecnológica en materia televisiva, en Televisa se estudiaron minuciosamente las diferentes alternativas disponibles que seguramente consideraría la industria televisiva mundial para establecer la llamada "televisión del mañana". Estas modalidades estarían encausadas a reemplazar a los sistemas hoy existentes: NTSC (National Television System Comitee de Estados Unidos), PAL (Phase Alternating Line, desarrollado por el científico Walter Bruch, investigador de la firma alemana Telefunken y cuya presentación pública se realizó en 1963) y el SECAM (Sequentiel Couleurá Mémorie, patentado en 1957 por el investigador francés Henry de France). Una vez realizados los estudios pertinentes, Televisa decidió descartar la Improved Definition Television (IDTV) y la Extended Definition Television (EDTV), alternativas que principalmente se han desarrollado en Estados Unidos como una especie de tecnologías televisivas complementarias al NTSC. ${ }^{7}$ Finalmente el poderoso consorcio mexicano se resolvió en favor de la HDTV. ${ }^{8}$

7 La Improved Definition Television (IDTV), presenta algunas mejorías sobre el sistema NTSC sin llegar a reemplazarlo, requiriendo para tal efecto un mínimo de acciones por parte de la Comisión Federal de Comunicaciones de los Estados Unidos (FCC). La Extended Definition Television (EDTV), sí alcanza a comprender algunos cambios a las emisiones bajo el estándar NTSC, pero que cumplen satisfactoriamente con los ordenamientos dispuestos por la FCC en el sentido de que los receptores deberán ser compatibles con el NTSC. Las modificaciones permisibles se establecerían sobre estos lineamientos: ensanchar la banda, extender la definición de imagen y la resolución vertical emitida por el estándar NTSC, además de todas las mejorías contempladas por los sistemas de IDTV.

8 De acuerdo con un artículo de Sonia Landau (1989), entonces directora del Bureau de Comunicaciones Internacionales e Información Política del Departamento de Estado de la Unión Americana y publicado en el Department of State Bulletin en junio del mismo año, en la denominación HDTV 
Mediante un comunicado de prensa que se dio a conocer a la opinión pública el 3 de septiembre de 1990, Televisa informó que ese mismo día se habían llevado a cabo exitosamente las p-imeras transmisiones de HDTV en la República Mexicana. Estas se realizaron desde el Cerro Pico de Tres Padres, ubicado al norte de la Ciudad de México y a una altura de $\mathbf{8 0 0}$ metros sobre el nivel de ésta, a las instalaciones de Televisa San Angel (localizadas a unos 25 kilómetros de distancia).

En este histórico suceso en el que se emplearon las bandas de 12 y 17 gigahertz, los técnicos de Televisa fueron asesorados por los ingenieros de la Nippon Hoso Kyokai - NHK - empresa televisiva japonesa con la que el consorcio mexicano llevó a cabo las negociaciones necesarias ${ }^{9}$ para adquirir los derechos que le permitirían incorporar el Sistema 1125/60 Alta VI, o HIGH VISION, de alta definición. ${ }^{10}$ La NHK empezó sus investigaciones en materia de HDTV desde 1971 y en realidad es la creadora de la televisión de alta definición. Cabe destacar que el sistema Alta Vi inicialmente había sido concebido para difundirse vía satélite, sin embargo, la referida transmisión se llevó a cabo mediante una antena terrestre.

Durante las primeras demostraciones de HDTV, a las que Televisa invitó a la cúpula empresarial mexicana, se afirmó que el sistema adquirido estaría operando comercialmente hacia finales de 1992, o principios de 1993. En realidad, como

(...) se incluyen a todos aquellos sistemas que pueden suponer implícitas mejorías contempladas en la IDTV y la EDTV, pero que requiere de la aprobación de la FCC. Cabe destacar que estos sistemas, sin llegar a tener la calidad de la HDTV, son superiores a los sistemas convencionales. La industria televisiva estadounidense ha tratado debido a los elevados gastos de reconversión que representa la HDTV. Por medio de estos sistemas se pretende que los televidentes estadounidenses desechen sus actuales receptores para empezar a reemplazarlos por los de la "televisión mejorada" que resultan más económicos que los sofisticados receptores de HDTV. Esta medida proteccionista en realidad obedece a que la ind ust ria televisiva estadounidense le interesa dilatar por todos los medios a su alcance la incorporación de la HDTV, pues ésta se encuentra en una incómoda situación de desventaja frente al Japón y a Europa, debido a su sensible atraso tecnológico en la materia. De cualquier manera, con el objeto de evitar sorpresas desagradables, la NHK también se ha preocupado pordesarrollar sistemas de televisión mejorada, comoel MUSE6(Las siglas MUSE significan Multiple Sub Myquist Sampling Encoding.)

9 En una interesante entrevista que realizó el periodista Javier Martínez Stainess (1991), a dos distinguidos funcionarios de Televisa - Alejandro Burillo Azcárraga y Alejandro Sada, éstos afirmaron, refiriéndose a la HDTV que: "Aunque tengamos que pelear con estadunidenses, holandeses y franceses, nos asociaremos con los japoneses para que México sea el primero que implante esta tecnología". La entrevista fue publicada en la revista Expansión, en mayo del mismo año.

10 En el artículo de Mejía Barquera y Sosa Plata (1992), los autores se refieren a una ent revista que sostuvieron con el ingeniero Jaime Robledo, quien puntualizó que el sistema que Televisa adquirió de la NHK es el Muse Narrow. 
acertadamente afirman Fernando Mejía Barquera y Gabriel Sosa Plata, ${ }^{11}$ será entre 1993 y 1998 cuando Televisa habrá puesto en funcionamiento la televisión de alta definición. Resulta imposible explicar las razones por las que Televisa estableció tan corto plazo para dar inicio a sus transmisiones de HDTV. Al momento de elaborar estas notas, el esperado comienzo de éstas aún no se había producido.

También por esos días, mediante un interesante boletín de prensa que me parece pertinente reproducir casi en su totalidad, Televisa dio a conocer que desde 1989 había realizado las gestiones necesarias con la Secretaría de Comunicaciones y Transportes para obtener la concesión de dos canales de "televisión restringida" - que es como en términos legales se define en México a un servicio no gratuito de imagen electrónica - por medio de los cuáles empezaría a operar la HDTV dentro del área metropolitana de la Ciudad de México:

Durante la visita que recientemente realizo a Japón el presidente Carlos Salinas de Gortari, la empresa NHK (Nippon Hoso Kyoai) llevó a cabo para él una demostración de la tecnologfa que se ha denominado "Hi Vision" o "High Definition". El Señor Presidente expres $\sigma$ en aquella ocasion que sería conveniente que se hiciera en nuestro país una demostración de esa tecnología que en español la NHK la ha nombrado Alta Vi (...) Vale la pena mencionar que esta tecnología desarrollada en Japón ha dado pie a innumerables comentarios tanto a favor como en contra en diversos lugares del mundo, quizá por que se le ha visualizado como una tecnología que sustituye a la televisión actualmente existente ya sea en su modalidad conocida como NTSC, que es la que se utiliza en la mayor parte de los países de América y de Asia, o bien de sus modalidades PAL o SECAM, que se utiliza en Europa. Televisa no comparte el criterio de identificar esta tecnologla como una sustitución técnica de la televisión actual, sino como una tecnologfa que brinda gran oportunidad de implementar nuevos servicios que ahora no existen, y por esa razon desde 1989 ha solicitado a la Secretaría de Comunicaciones y Transportes la concesión para operar dos canales de "televisión restringida" para ofrecer al público subscriptor en el Valle de México lo que podría denominarse como "cine electrónico", que ofrecería películas y espectáculos y, en general, imágenes y sonido con la más alta calidad. El cine electrónico permitiría al público disfrutar del estreno de películas en la comodidad de su hogar y con la calidad

11 Estos autores señalan que: "Los años comprendidos entre 1993 y 1998 serán de enorme importancia para la radio y la televisión en México. En este lapso se colocarán los fundamentos de una transformación tecnológica que repercutirá en los sistemas y equipos necesarios para realizar la transmisión y la recepción televisiva y radiofónica, pero también, por supuesto, en los hábitos de la gente a exponerse a estos medios". Se recomienda consultar el referido artículo de la revista Intermedios. 
de imagen y sonido que pemite esta nueva tecnología Alta Vi. La implementación en nuestro país de servicios como "el cine electrónico", utilizando esta tecnologra, para la cual todavía no existe en el mundo producción de aparatos receptores, permitiŕa que esa producción se realizara en nuestroterritorio con lasventajas derivadas de la inversion en instalaciones industriales, lo que significarfa la apertura de nuevas fuentes de trabajo y, sobretodo, ofrecería la posibilidad de una operación exportadora de gran volumen, situación ahora más necesaria que nunca, cuando tenenemos a la vista las negociaciones para el Tratado de Libre Comercio con nuestros vecinos del norte... (Es) posible pensar en implementar el servicio de "cine electrónico" en quizá doce meses y en que merced a ello, México consolide una posición de vanguardia en este ámbito. NHK ha aceptado la responsabilidad del diseno del sistema que permitirá la operación de los servicios antes mencionados y de la coordinación en la fabricación de los equipos necesarios.

Posiblemente Televisa presentará a través de estos canales de uso restringido eventos deportivos, películas y musicales, o bien el consorcio instale su propia red de salas especiales de "cinema electrónico" - especie de videoteatros - situación que le facilitaría superar el grave obstáculo que hoy representan los elevados costos de los receptores especiales que demanda esta nueva tecnología (que van de 5 mil hasta más de $\mathbf{3 0}$ mil dólares), cuya definición y nitidez le permiten al televidente distrutar de unas imágenes semejantes a las logradas por el cine, y que hasta ahora han resultado inaccesibles para las normas televisivas convencionales.

\section{El imperio electrónico y su laberinto}

En la actualidad, un considerable número de empresas se encuentran involucradas en el desarrollo de la HDTV. Lógicamente cada una de éstas aspira a que su sistema sea adoptado por el mayor número posible de países. La razón nos la dan a conocer claramente Mejía Barquera y Sosa Plata (1992), quienes afirman que

ello traería consigo un gran negocio por el pago de derechos o royalties para utilizar patentes y promover la venta de equipos de transmisión y recepción”.

La Comisión Federal de Comunicaciones de Estados Unidos ha sido prácticamente rebasada en su propósito de determinar el estándar único para regular la televisión de alta definición. Los complicados intereses políticos y comerciales de las empresas y naciones involucradas en el desarrollo de esta sofisticada tecnología categoricamente lo impiden. Inclusive Estados Unidos “ha jugado a la segura" y optará por 
un sistema evidentemente desarrollado por la misma industria televisiva estadounidense - posiblemente el Digi Cypher-.

En esa misma nación, durante el mes de febrero de 1990 , se dio a conocer el proyecto Sky Cable, con el que se pretende lanzar al mercado un sistema de DBS con 108 canales de HDTV, que serían recibidos mediante antenas parabólicas pequeñas y planas. En este ambicioso proyecto se encuentran involucradas la NBC, Hughes Communications, Cablevision y The News Corporation, propiedad de Rupert Murdoch, célebre empresario australiano de la industria de las comunicaciones.

Además de los sistemas desarrollados por japoneses y estadounidenses, hay que considerar que varios países de la Comunidad Europea iniciaron hace unos años sus propios trabajos en materia de HDTV con el proyecto Eureka 95, en el que participan empresas como Thomson, Philips, Bosch y Thorm Emi (Vannuchi, 1990).

Sin embargo, así como aún no existe acuerdo en lo relativo a los estándares con los que habrá de operar la HDTV, la industria televisiva mundial también deberá determinar la mejor manera de introducirla, ya sea mediante antenas terrestres, transmisiones por cable, o a través de satélites de difusión directa.

Hasta el momento, en México no se han dado a conocer las normas sobre las que habrá de funcionar la HDTV. La delicada situación la exponen perfectamente Mejía Barquera y Sosa Plata (1992):

"La pregunta es: ¿Qué sucederá si cuando en Estados Unidos se aprueben las normas técnicas para la HDTV que regirán en ese país, el gobierno mexicano decide adoptarlas considerando la estrecha relación económica entre México y Estados Unidos y el flujo de compraventa de aparatos receptores que existe entre ambas naciones, debido a que comparten el mismo sistema de televisión (el NTSC)?.

Al decidirse Televisa por adoptar el sistema Alta Vi de la NHK de Japón, corre el inevitable riesgo de que en Estados Unidos se determine el uso de un sistema diferente e inclusive hasta incompatible. Al parecer, México seguramente tendrá que establecer ciertas normas para la HDTV por satélite y otras para la HDTV transmitida por vía terrestre. Es factible que Televisa negocie ante la NHK la posibilidad de comercializar en exclusiva los receptores especiales que demanda el sistema que adquirieron de ésta. 
Sin embargo, de la firma del Tratado de Libre Comercio pueden derivarse indeseables incomodidades para Televisa. No sería nada extraño que debido a los nexos de mayor proximidad que pronto estableceremos con nuestros vecinos del norte se desprendan posibles negociaciones en materia de telecomunicaciones - terreno en el que hasta ahora el Estado Mexicano ha decidido no transigir - de las que Televisa podría llevarse una desagradable sorpresa.

En fin, de no ocurrir alguna situación inesperada, en los próximos cinco años Televisa, la primera cadena televisiva en el mundo en horas exportadas de programación, ${ }^{12}$ se encontrará operando el sistema de alta definición que adquirió de la NHK. Sin embargo, seguramente será hasta el año 2000 cuando esta tecnología se encuentre en condiciones de sustituir a la televisión convencional que conocemos hoy en día.

\section{Referencias bibliográficas}

Aguilar Camín Héctor (1988): Después del milagro. México: Cal y Arena.

FUENTES Carlos (197?): Tiempo mexicano. México: Joaquín Mortiz.

Mejfa Barquera Fernando y Gabriel Sosa Plata (1992): "Radio digital y televisión de alta definición en México". Intermedios Núm.5 (diciembre).

Oriol Costa Pere (1986): La crisis de la televisión pública. España: Paidós.

VANNUCHI G. (1990): “A new frontier in image transmission: high definition television (HDTV)". Revista Telettra Review (Contributions to Telecommunications Development) Núm. 43 (junio).

12 Conforme con lo señalado al periodista Martínez Stainess (1991), por los funcionarios de Televisa. 